\title{
Soil Washing of Cyanide Contaminated Soil with Phosphate Solution
}

\author{
Jae Gon Kim \\ Korea Institute of Geoscience and Mineral Resources \\ 124 Gwahag-ro Yuseong-gu Daejeon 34132 Korea \\ jgkim@kigam.re.kr
}

\section{Extended Abstract}

A large amount of cyanide has been produced and used in a variety of industrial processes such as metal plating, gas production, mining and pigment production. Cyanide in environment has attracted a concern due to its high toxicity. Toxicity and mobility of cyanide in soil are strongly depending on its form [1]. Chemical oxidation and biological degradation are commonly adopted for the remediation of cyanide contaminated soil [2]. The chemical oxidation with the direct injection of oxidants revealed a limited remedial efficiency due to the degradation of oxidants by organic matter, manganese oxide and sulphide and to the low oxidation rate of adsorbed metal cyanide complex and solid metal cyanide.

We tried to develop the washing method with a phosphate solution for the remediation of cyanide contaminated soil. The cyanide contaminated soil was collected at a gold mine site in Korea and was air-dried. The air-dried soil sample $(<2$ $\mathrm{mm}$ in diameter) contained $85 \mathrm{mg} \mathrm{kg}^{-1}$ of cyanide and used in the experiment for the technology development. The kinetic study and the washing efficiency test were conducted with the reaction of 1 soil and 5 washing solution. The washing solutions contained $0-100 \mathrm{mM}$ Na-orthophosphate, Na-hexametaphosphate or Na-pyrophosphate and the $\mathrm{pH}$ of solutions was adjusted to $10-12$ with $1 \mathrm{~N} \mathrm{NaOH}$. After the reaction, the $\mathrm{pH}$ and the concentrations of cyanide species (free, weak acid dissociable and strong acid dissociable) and heavy metals of the solutions were determined.

The extracted amount of cyanide from the soil sharply increased with increasing reaction time until 100 minutes and then the extraction rate slowly increased. The cyanide extraction rate was gradually increased with increasing the solution $\mathrm{pH}$. The cyanide extraction rate sharply increased with increasing phosphate concentration of the washing solution until 30 $\mathrm{mM}$ and then the extraction rate slowly increased. The cyanide extraction efficiency of the phosphate species at the same $\mathrm{pH}$ and the same concentration revealed as following: pyrophosphate $>$ hexametaphosphate $>$ orthophosphate. The optimum washing solution for cyanide extraction among the tested solutions was the $\mathrm{pH} 1230 \mathrm{mM}$ Na-hexametaphosphate solution. Ninety seven percent of the soil cyanide were extracted by reacting with the optimum washing solution for 30 minutes. The As concentration of the solution after the reaction increased with increasing the $\mathrm{pH}$ and the phosphate concentration of the washing solutions. The experimental data indicate that the soil washing with alkali phosphate solution can be successfully applied for the remediation of cyanide contaminated soil with an attention on As desorption during washing.

\section{References}

[1] P. Kjeldsen, "Behaviour of cyanide in soil and groundwater: a review," Water, Air, and Soil Pollution, vol. 115, no. 2, pp. 290-307, 1999.

[2] A. Akcil, "Destruction of cyanide in gold mill effluents: biological versus chemical treatment," Biotechnology Advances, vol. 21, no. 3, pp. 501-511, 2003. 